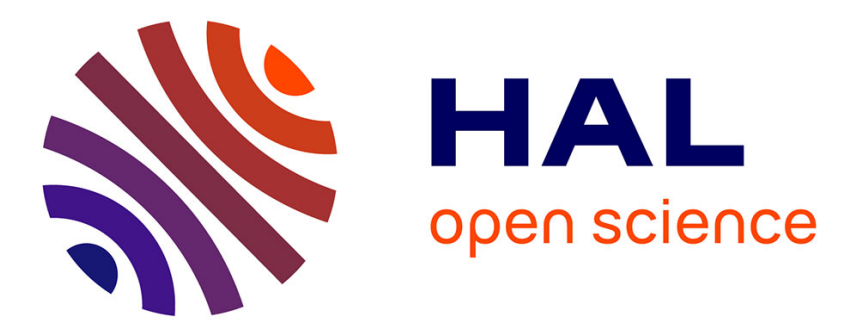

\title{
Energy Balance in Cavitation Erosion: From Bubble Collapse to Indentation of Material Surface
}

Regiane. Fortes Patella, Guillaume Challier, Jean-Luc Reboud, Antoine

Archer

\section{- To cite this version:}

Regiane . Fortes Patella, Guillaume Challier, Jean-Luc Reboud, Antoine Archer. Energy Balance in Cavitation Erosion: From Bubble Collapse to Indentation of Material Surface. Journal of Fluids Engineering, 2013, 135 (1), 10.1115/1.4023076 . hal-00980543

\section{HAL Id: hal-00980543 https://hal.science/hal-00980543}

Submitted on 2 Mar 2020

HAL is a multi-disciplinary open access archive for the deposit and dissemination of scientific research documents, whether they are published or not. The documents may come from teaching and research institutions in France or abroad, or from public or private research centers.
L'archive ouverte pluridisciplinaire HAL, est destinée au dépôt et à la diffusion de documents scientifiques de niveau recherche, publiés ou non, émanant des établissements d'enseignement et de recherche français ou étrangers, des laboratoires publics ou privés.

\section{(ㄷ)(1)}

Distributed under a Creative Commons Attribution| 4.0 International License 


\section{Energy Balance in Cavitation Erosion: From Bubble Collapse to Indentation of Material Surface}

An original approach based on energy balance between vapor bubble collapse, emitted pressure wave, and neighboring solid wall response was proposed, developed, and tested to estimate the aggressiveness of cavitating flows. In the first part of the work, to improve a prediction method for cavitation erosion (Fortes-Patella and Reboud, 1998, "A New Approach to Evaluate the Cavitation Erosion Power," ASME J. Fluids Eng., 120(2), pp. 335-344; Fortes-Patella and Reboud, 1998, "Energetical Approach and Impact Efficiency in Cavitation Erosion," Proceedings of Third International Symposium on Cavitation, Grenoble, France), we were interested in studying the pressure waves emitted during bubble collapse. The radial dynamics of a spherical vapor/gas bubble in a compressible and viscous liquid was studied by means of Keller's and Fujikawa and Akamatsu's physical models (Prosperetti, 1994, "Bubbles Dynamics: Some Things we did not Know 10 Years Ago," Bubble Dynamics and Interface Phenomena, Blake, Boulton-Stone, Thomas, eds., Kluwer Academic Publishers, Dordrecht, the Netherlands, pp. 3-15; Fujikawa and Akamatsu, 1980, "Effects of Non-Equilibrium Condensation of Vapor on the Pressure Wave Produced by Collapse of a Bubble in Liquid," J. Fluid Mech., 97(3), pp. 481-512). The pressure amplitude, the profile, and the energy of the pressure waves emitted during cavity collapses were evaluated by numerical simulations. The model was validated by comparisons with experiments carried out at Laboratoire Laser, Plasma et Proce'd'es Photoniques (LP3-IRPHE) (Marseille, France) with laser-induced bubble (Isselin et al., 1998, "Investigations of Material Damages Induced by an Isolated Vapor Bubble Created by Pulsed Laser," Proceedings of Third International Symposium on Cavitation, Grenoble, France; Isselin et al., 1998, "On Laser Induced Sin-gle Bubble Near a Solid Boundary: Contribution to the Understanding of Erosion Phe-nomena," J. Appl. Phys., 84(10), pp. 5766-5771). The efficiency of the first collapse $g_{\text {wave/bubble }}$ (defined as the ratio between pressure wave energy and initial bubble poten-tial energy) was evaluated for different bubble collapses. For the cases considered of col-lapse in a constant-pressure field, the study pointed out the strong influence of the air contents on the bubble dynamics, on the emitted pressure wave characteristics, and on the collapse efficiency. In the second part of the study, the dynamic response and the sur-face deformation (i.e., pit profile and pit volume) of various materials exposed to pressure wave impacts was simulated making use of a $2 \mathrm{D}$ axisymmetric numerical code simulating the interaction between pressure wave and an elastoplastic solid. Making use of numerical results, a new parameter b (defined as the ratio between the pressure wave energy and the generated pit volume) was introduced and evaluated for three materials (alumi-num, copper, and stainless steel). By associating numerical simulations and experimental results concerning pitted samples exposed to cavitating flows (volume damage rate), the pressure wave power density and the flow aggressiveness potential power were intro-duced. These physical properties of the flow characterize the cavitation intensity and can be related to

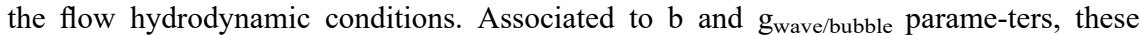
power densities appeared to be useful tools to predict the cavitation erosion power.

\section{R. Fortes-Patella1}

regiane.fortes@legi.grenoble-inp.fr

G. Challier2

LEGI, Grenoble INP, BP 53, 38041

Grenoble

Cedex 9, France

J. L. Reboud

G2ELab, CNRS, Institut

Polytechnique, Grenoble and Joseph

Fourier University, BP

166, 38042 Grenoble Cedex 9, France

jean-luc.reboud@ujf-grenoble.fr

A. Archer

EDF R\&D, 78401 Chatou, France e-mail: antoine.archer@edf.fr

\section{Introduction}

Despite the numerous and important works that have been developed in the field of cavitation erosion (for example, Refs. [1-6]), the analysis and the prediction of erosion mechanisms remain a big challenge for researchers and industrial partners. Reliable studies developed in this area have to take into account several very complex coupled phenomena: cavitating flows are unsteady, three-dimensional, turbulent, and multiphase, character-

\footnotetext{
${ }^{1}$ Corresponding author.

${ }^{2}$ Present address: Snecma, Forêt de Vernon, BP 802, 27208 Vernon, France.
}

ized by regions of high or low compressibility. The collapses of vapor structures lead to pressure wave emissions of high amplitude ( $\sim \mathrm{GPa})$ and very short duration (ns to $\mu \mathrm{s})$ [7]. The emitted pressure waves interact with neighboring solid walls, the material damage is characterized by high stress level and strain rates, and the mass loss period includes fatigue and/or material strain hardening phenomena. The mechanical properties of the material exposed to cavitation impacts are very difficult to evaluate.

The present work is a part of a global scenario, which allows the development of a new method of cavitation erosion prediction. The physical scenario is illustrated in Fig. 1. It is based on an energy balance between vapor structures collapses, emitted pressure waves, and material damage. With the aim to propose a 


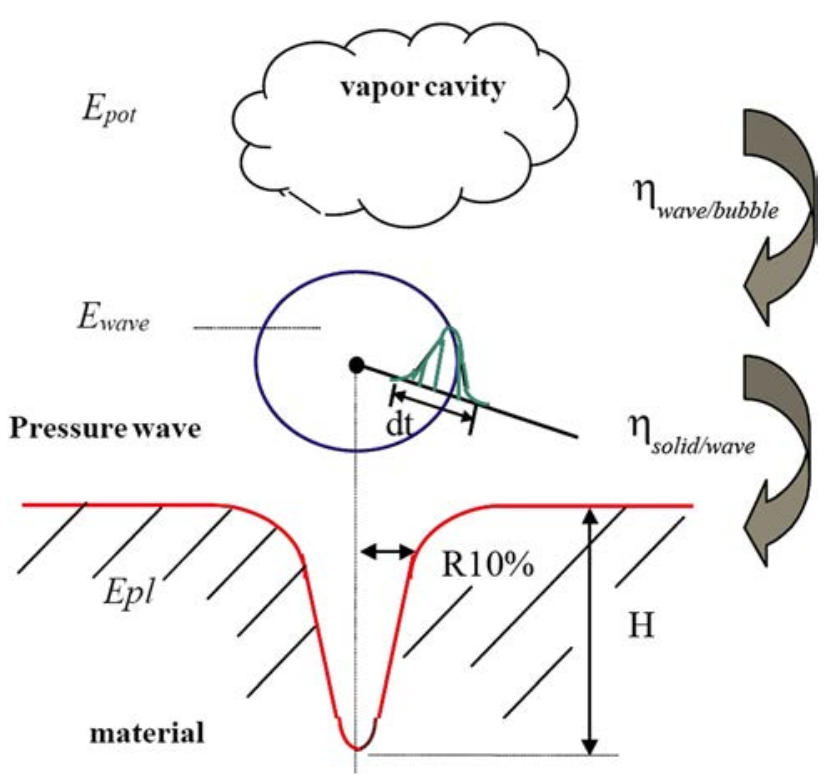

Fig. 1 Scheme of the proposed physical model-pressure wave emitted during the collapse of vapor structures is considered to be the phenomenon responsible for material damage. The collapse of vapor cavities is characterized by potential energy $E_{\text {pot }}$ (related to the pressure gradient and to the cavity volume) and by collapse efficiency $\eta_{\text {wave/bubble; the emitted pres- }}$ sure wave is characterized by the acoustic energy $E_{\text {wave; }}$ the material damage is described by the indentation volume $V_{\text {pit }}=f\left(R_{10 \%}, H\right)$.

global physical model, this work presents a summary of some results presented previously in two conferences [8,9].

In this first part of the work, we study energy transfers between spherical bubble collapses and the generated pressure waves. Mainly, the collapse efficiency $\eta_{\text {wave/bubble }}$ is defined and evaluated for different bubble energies, environmental pressures, and air content.

The second part of the work describes the interaction between a spherical pressure wave propagating in the water and a neighboring solid surface. Making use of energy distributions, erosive efficiency $\eta_{\text {solid/wave }}$ is defined and calculated for three materials (aluminum, copper, and stainless steel). Based on this approach, a prediction method of cavitation erosion is proposed and applied to analyze sample surfaces exposed to different cavitating flows.

\section{Bubble Dynamics}

Cavitation phenomena, characterized by inception, growth, and collapse of vapor/gas structures, are generally associated with the dynamics of bubbles. A cavitation bubble is formed from a small air bubble in water (cavitation nuclei) when surrounding pressure decreases, and then it collapses with the surrounding pressure rise. During the early stages of cavitation bubble collapse, the walls of the cavity contract extremely rapidly, increasing the bubble pressure to a very high level (GPa). The immediate vicinity of the collapsing bubble is characterized by a spherical pressure wave, which propagates at about the sound speed in the host liquid.

Since Rayleigh's work [10], the bubbles' dynamics have been investigated by many researchers [11-18]. In those studies, phenomena such as liquid compressibility, deformation of bubble from the spherical shape near a solid wall, thermal effects, and/or mass diffusion have been considered. More precisely, the acoustic transients emitted during spherical bubble collapses were studied by Refs. [14,19] making use of hydrophone, optical detection, and high-speed interferometer techniques. They have determined the pressure amplitude, the profile, and the energy of the pressure waves emitted by optical cavitation in water.
In previous works [7], we compared several experimental and numerical pit profiles produced in test materials by different cavitating flows. Comparison of indentation shapes on solid surfaces indicated that high pressure waves emitted during the collapses of vapor structures were the main factor contributing to cavitation damage. The emission of the pressure wave can be generated either by spherical bubble or vortex collapses (as observed by Refs. $[14,18,20,21])$ as well as by microjet formation $[22,23]$.

Moreover, in real cavitating flows, bubble clouds can be frequently observed and seem to be closely related to the severe cavitation damage [24-26]. In a bubble cloud, the interaction between bubbles leads to a consecutive sequence of collapses: The pressure wave emitted during the collapse of a bubble interacts with neighboring bubbles, amplifies their collapses, and then may increase the erosive power of the flow.

In order to evaluate the aggressiveness power of cavitating flows and to improve a prediction method for cavitation erosion, we are first interested in studying the pressure wave emitted during bubble collapses.

Sections 3 and 4 present a theoretical and numerical analysis of pressure waves emitted during spherical bubble collapses. The Herring-Keller equation [27] and the empirical state law of Tait are applied to simulate numerically the dynamic behavior of cavitation bubbles in water and mainly to evaluate the energy, the amplitude, and the passage time of the pressure wave emitted. A dimensionless study, relating the bubble parameters (radius $R_{0}$, initial gas pressure $p_{g 0}$, liquid pressure $p_{\infty}$ ) with the characteristics of the pressure wave (amplitude and passage time) is proposed. Mainly, the influence of the air content on the emitted pressure wave is evaluated.

By using the potential energy of the initial bubble, or cavity, and the emitted pressure wave energy, the collapse efficiency $\eta_{\text {wave/bubble }}$ is defined and evaluated for bubbles imploding under different hydrodynamic conditions (Sec. 5).

\section{Bubble Model}

The first analytical model to describe the dynamic behavior of cavitation bubbles was proposed in Ref. [10]. In that model, the liquid is assumed to be incompressible, and the results are satisfactory only for small amplitudes of bubble oscillations. The influence of the fluid compressibility, of the surface tension, and of the viscous effects on bubble dynamic was introduced in Refs. [28-30], respectively. Those three effects were considered in Ref. [27], which proposed a more precise model based on the Keller's approach [31]. The equation of the motion has the form,

$$
\begin{aligned}
& {\left[1-\frac{\dot{R}}{\mathbf{c}_{\mathrm{liq}}}\right] R \ddot{R}+\frac{3}{2}\left[1-\left(\frac{1}{3}\right) \frac{\dot{R}}{c_{\mathrm{liq}}}\right] \dot{R}^{2}=\left[1+\frac{\dot{R}}{\mathbf{c}_{\mathrm{liq}}}+\frac{R}{\mathbf{c}_{\mathrm{liq}}} \frac{d}{d t}\right] \frac{p_{B}}{\rho}} \\
& p_{B}=p_{v}+p_{g}-p_{\infty}(t)-\frac{2 \sigma}{R}-\frac{4 \mu}{R} \dot{R}
\end{aligned}
$$

where $R$ is the bubble radius, $c_{\text {liq }}$ is the sound speed in the liquid (assumed constant according to the acoustical approximation), $p_{v}$ and $p_{g}$ are the vapor pressure and the gas pressure inside the bubble, $\mu$ is the liquid viscosity; $\sigma$ is the surface tension; $\rho$ is the liquid density, and $p_{\infty}$ is the pressure at infinity. The gas pressure inside the bubble is calculated considering isentropic conditions,

$$
p=p_{g 0}\left(\frac{R_{0}}{R}\right)^{3 \gamma}
$$

where $p_{g 0}$ and $R_{0}$ are, respectively, the initial gas pressure and bubble radius, and $\gamma$ is the ratio of the specific heats $(\gamma=1.4$ for air in the case of isentropic transformation).

Considering the Kirkwood-Beth approximation, Ref. [32] introduced the enthalpy and the sound speed at the bubble wall. This model, more complex than the ones described here above, is suitable even for the largest amplitudes of the bubble oscillations. 
In the case of subsonic flows, results obtained by Keller's and Gillmore's models were considered similar in Ref. [11]. Hence, in the present study, Keller's approximation was applied to describe the bubble dynamic and to simulate pressure wave emission. Summarizing, the following assumptions are made: the bubble is spherically symmetric; the surrounding liquid is infinite, compressible, and viscous; the effect of the interaction between compressibility and viscosity is negligible; the effects of gravity and diffusion are negligible; the pressure inside the bubble is uniform; the noncondensable gas is inviscid and obeys the perfect-gas law; the physical properties of liquid and gas are constant; and heat conduction and thermal effects are not taken into account.

\section{Pressure Wave Simulations}

4.1 Applied Models. To simulate the time and spatial pressure distribution throughout the liquid during bubble collapse, the study considers:

(a) The empirical isotropic state law of Tait, given by Ref. [33]

$$
\frac{p+B}{p_{\infty}+B}=\left(\frac{\rho}{\rho_{\infty}}\right)^{n}
$$

where $p$ is the liquid pressure, $p_{\infty}$ is the pressure at infinity, $\rho$ is the liquid density, and $\rho_{\infty}$ is the density at infinity. $B$ is $3010 \mathrm{~atm}$ and the index $n$ is 7.15 for water. Although this relation has not been validated for high pressures (the order of GPa), we decided to use it due to the lack of any better law.

(b) Fujikawa and Akamatsu introduced in Ref. [12] the velocity potential $\phi(r, t)$ for the compressible liquid motion, summarizing the continuity equation and the momentum equation take as

$$
\frac{\partial \phi}{\partial t}+\frac{1}{2}\left(\frac{\partial \phi}{\partial r}\right)^{2}+\int \frac{d p}{\rho}=\frac{c_{\mathrm{liq}}^{2}}{n-1}
$$

where $t$ is the time, $r$ is the radial distance from the center of the bubble, and $c_{\text {liq }}$ is the sound speed in the liquid at infinity. The first-order approximation of $\phi$ proposed by the authors relates to the spherical bubble radius as

$$
\phi=-\frac{1}{r}\left[R^{2} \dot{R}-\frac{R^{2}}{c_{\mathrm{liq}}}\left(2 \dot{R}^{2}+R \ddot{R}\right)\right]
$$

Hence, the pressure distribution in the liquid can be found

$$
\begin{aligned}
p(r, t)= & -B+\left(p_{\infty}+B\right)\left\{1-\frac{n-1}{c_{\mathrm{liq}}^{2}}\right. \\
& \times\left[\frac{1}{2 r^{4}} R^{2} \dot{R}-\frac{2 R^{2} \dot{R}^{2}}{c_{\mathrm{liq}}}-\frac{R^{2} \ddot{R}}{c_{\mathrm{liq}}}\right)^{2} \\
& +\frac{1}{r}-R^{2} \ddot{R}-2 R \dot{R}^{2} \\
& \left.\left.\left.+\frac{R}{c_{\mathrm{liq}}}\left(4 \dot{R}^{3}+7 R \dot{R} \ddot{R}+R^{2} \ddot{R}\right)\right)\right]\right\}^{\frac{n}{n-1}}
\end{aligned}
$$

In the present work, the differential equations were numerically integrated by the fourth order Runge-Kutta method. The collapse of a spherical bubble of initial radius $R_{0}$ containing both vapor and noncondensable gas in a viscous compressible liquid was studied. Moreover, the emitted energy was compared to initial bubble potential energy $E_{\text {pot }}$ defined as the product of initial bubble volume and pressure imbalance $p_{\infty}-p_{v}$.

4.2 First Example of Application. For validation, the proposed model was firstly compared with the work of Ref. [12]. The following initial conditions were chosen: $R_{0}=0.1 \mathrm{~mm}$, $p_{\infty}=0.7025 \mathrm{~atm}, p_{g 0}=702.5 \mathrm{~Pa}$, and $p_{v}=2300 \mathrm{~Pa}$. Figure 2 illustrates the time distribution of the pressure signal and the history of the bubble radius obtained by our numerical simulation. Bubble minimum radius is $\sim 0.005 \mathrm{~mm}$, and the attained maximum impulsive pressure is about $1900 \mathrm{~atm}$. In comparison, by taking into account finite mass transfer rate and thermal effects and making use of a second order approximation for the velocity potential, Ref. [12] obtained $\sim 0.004 \mathrm{~mm}$ and $\sim 2200 \mathrm{~atm}$, respectively (the relative error on the maximum impulsive pressure evaluation is about $15 \%$ ). The differences are due mainly to the effects of thermal conduction in the case of small bubble radius. According to Ref. [12], the thermal diffusion length $l$ within the bubble is proportional to $R_{0}{ }^{0.5}$ and the ratio $\left(l / R_{0}\right)$ varies as $R_{0}{ }^{-0.5}$. For a bubble of $R_{0}=1 \mathrm{~mm}$, for example, the relative difference between maximum impulsive pressures calculated by both approaches is about $4 \%$.

From Fig. 2(b), the influence of the liquid compressibility is clear. At high pressure, the dependence of pressure amplitude on radial distance deviates from the inverse proportional relation $p \sim$ $r^{-1}$ (given in Ref. [12]) and tends toward $p \sim r^{-1.5}$ as observed also in Ref. [19]. This was verified experimentally in Ref. [34], which indicates some difficulties to use piezoelectric sensors to measure wave amplitude for small distance $r$.

Pressure waves created by bubble collapses are characterized by the emitted energy $E_{\text {wave }}$, which can be evaluated in a simple way by the acoustic energy approach $[14,19,35]$
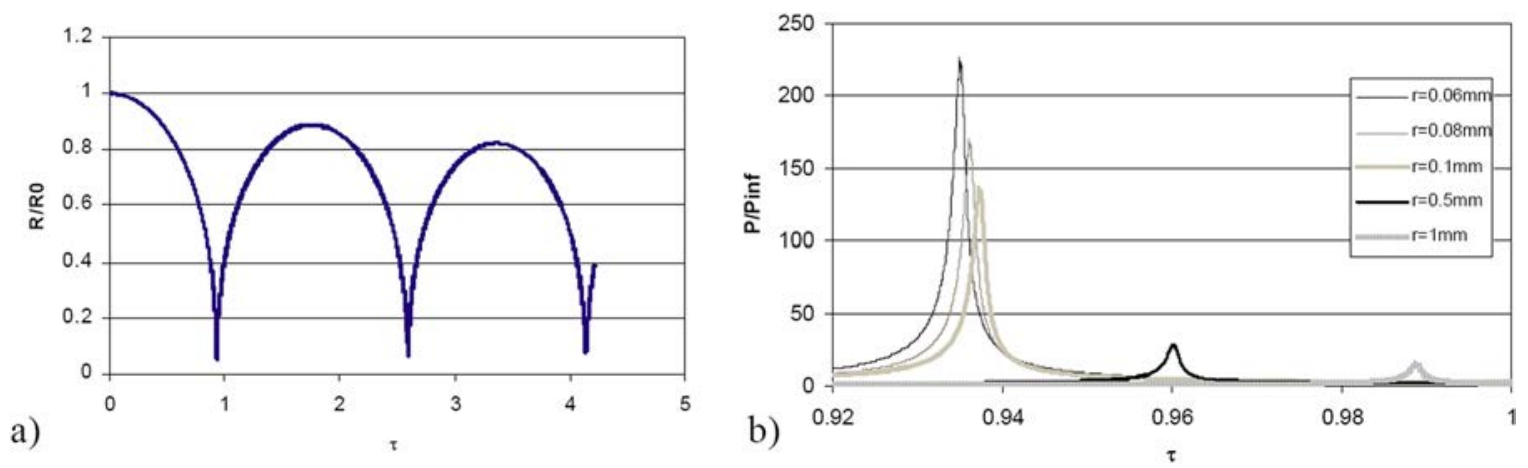

Fig. 2 (a) History of bubble radius; (b) time distribution of the pressure signal at different radius. For this example: $R_{0}=0.1 \mathrm{~mm} ; p_{\infty}=0.7025 \mathrm{~atm} ; p_{g 0}=702.5 \mathrm{~Pa}$. 


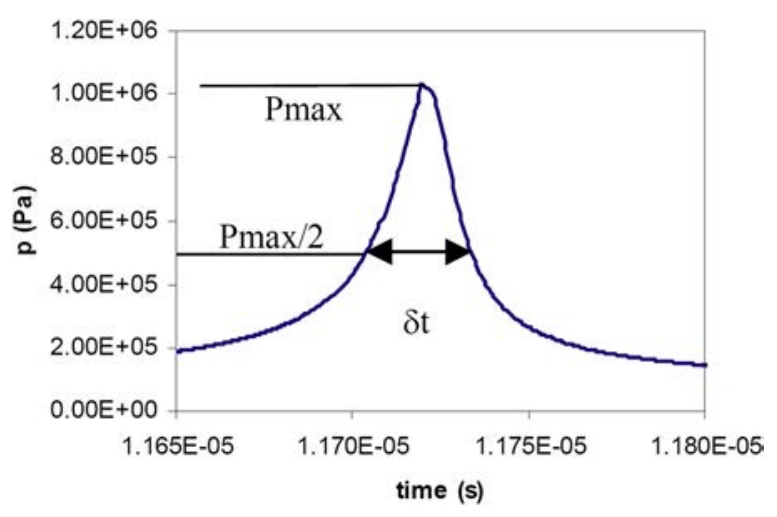

Fig. 3 Time distribution of the pressure signal at $r=1 \mathrm{~mm}$ from bubble center: the wave passage time $\delta t$ is given by the pressure signal width at $p=p_{\max } / 2$

Table 1 Results obtained by acoustic approach. Bubble initial energy is $E_{\text {pot }} \sim 0.3 \mu \mathrm{J}$.

\begin{tabular}{lccc}
\hline \hline$r(\mathrm{~mm})$ & $\delta t(\mathrm{~ns})$ & $E_{a c}(\mu \mathrm{J})$ & $\eta_{\text {wave/bubble }}$ \\
\hline 0.06 & 26 & 0.1 & $35 \%$ \\
0.08 & 26 & 0.1 & $35 \%$ \\
0.1 & 26 & 0.1 & $35 \%$ \\
0.5 & 27 & 0.11 & $38 \%$ \\
1.0 & 28 & 0.12 & $42 \%$ \\
\hline \hline
\end{tabular}

$$
E_{\mathrm{wave}} \approx E_{a c}=\frac{4 \pi r^{2}}{\rho c_{\mathrm{liq}}} \int p^{2} d t \approx \frac{4 \varsigma \pi p_{\max }^{2} r^{2}}{\rho c_{\mathrm{liq}}} \delta t
$$

where $p$ is the transient pressure signal at a given radius $r, p_{\max }$ is the peak of the pressure signal, $c_{\text {liq }}$ is the pressure wave celerity, $\rho$ is the fluid density, and $\delta t$ is the wave passage time. The wave passage time (Fig. 3) is given by the pressure signal width at $p=p_{\max } / 2$. The integration factor $\zeta$ is related to the wave form of the pressure signal. This method was also used in Ref. [36] to determine the acoustic energy spectrum and the noise level due to bubble collapses.

The wave passage time $\delta t$ and the wave energy are evaluated from the pressure signals. Table 1 presents results obtained for the given example at different radii $r$. The wave passage time is almost constant (about $26 \mathrm{~ns}$ ) as experimentally observed in Ref. [34].

Comparison can be done with instantaneous integration of the total energy in the spherical pressure wave (the kinetic energy is neglected) [37]

$$
E_{\mathrm{wave}} \approx E_{\mathrm{tot}} \approx \int\left(\Delta h-\frac{\Delta p}{\rho}\right) 4 \pi \rho r^{2} d r
$$

where $\Delta h=h-h_{\infty}$ (enthalpy given by the Tait state law)

$$
E_{\mathrm{tot}}=\int\left(\frac{n}{n-1} \frac{p_{\infty}+B}{\rho_{\infty}}\left(\left(\frac{p+B}{p_{\infty}+B}\right)^{\frac{n-1}{n}}-1\right)-\frac{\Delta p}{\rho}\right) \rho \cdot 4 \cdot \pi \cdot r^{2} d r
$$

$\Delta p=p-p_{\infty}, p$ is the instantaneous spatial pressure signal, and $p_{\infty}$ is the surrounding pressure.

In the given case, numerical spatial integrations of Eq. (7) give, at different times, a constant total energy $E_{\text {tot }}=0.09 \mu \mathrm{J}$, about $10 \%$ smaller than the result given by the acoustic wave approximation.

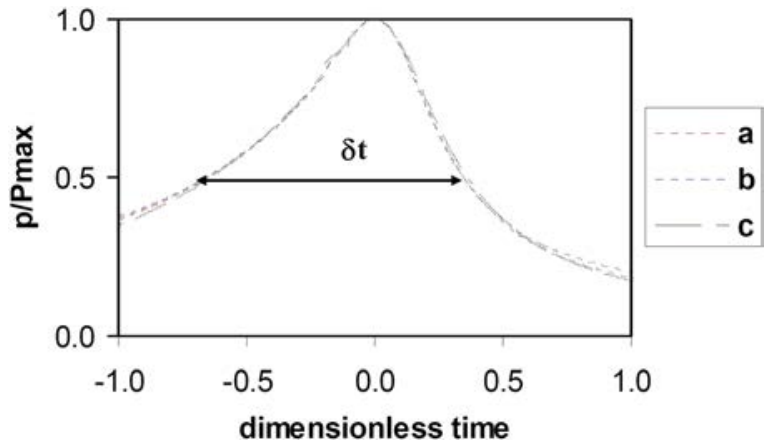

Fig. 4 Dimensionless pressure $\left(p / p_{\max }\right)$ versus dimensionless time $(t / \delta t)$ in different cases with $p_{\infty}=1$ bar; (a) $R_{0}=1 \mathrm{~mm}$, $p_{g 0}=1000 \mathrm{~Pa}, r=1 \mathrm{~mm} ;(b) R_{0}=1 \mathrm{~mm}, p_{g 0}=200 \mathrm{~Pa}, r=0.1 \mathrm{~mm}$; (c) $R_{0}=0.1 \mathrm{~mm}, p_{g 0}=500 \mathrm{~Pa}, r=1 \mathrm{~mm}$

4.3 Parametric Study. The bubble parameters considered in this study are the water pressure at infinity $p_{\infty}$, the initial radius of the bubble $R_{0}$ and the initial gas pressure within the bubble $p_{g 0}$. As indicated in the previous paragraph, the pressure wave emitted by bubble collapse can be characterized by two parameters: the wave amplitude $p_{\max }$ and the wave passage time $\delta t$, given by the pressure signal width at $p=p_{\max } / 2$. In Fig. 4 , for the $Y$-axis one draws $p / p_{\max }$, and for the $X$-axis one draws $t / \delta t$ so that the maximum be obtained for $x=0$. For this Fig. 4 we kept $p_{\infty}$ equal to 1 bar. We computed the transient pressure evolution for different initial radii $\left(R_{0}=0.1 \mathrm{~mm}\right.$ and $\left.R_{0}=1 \mathrm{~mm}\right)$, initial gas pressure $\left(p_{g 0}\right.$ equal to 200 and $1000 \mathrm{~Pa}$ ) and at different distances from the center of the bubble $\left(0.1 * R_{0}, R_{0}\right.$, and $\left.10 R_{0}\right)$.

4.3.1 A Constant Dimensionless Pressure Wave. As we can see in Fig. 4, the same shape for the dimensionless pressure wave is obtained whatever the initial conditions for the bubble are.

Hence, both wave parameters ( $p_{\max }$ and $\delta t$ ) depend on the bubble characteristics (given by $R_{0}, p_{\infty}$ and $p_{g 0}$ ). In order to discuss the evolution of the wave passage time $\delta t$, we drew the dimensionless number $c_{\text {liq }} \cdot \delta t / R_{0}$ versus $p_{g 0} / p_{\infty}$ for different values of the initial radius $R_{0}$ of the surrounding pressure $p_{\infty}$ and of $p_{g 0}$ (Fig. 5).

4.3.2 Gas Content Influence. It appears a strong influence of $p_{g 0} / p_{\infty}$ on the bubble dynamics and mainly on the emitted pressure wave passage time. It is worth noting that the initial gas pressure $p_{g 0}$ inside the bubble is related to the air content in the water. Brennen [38] has performed measurements in a supercavity behind a sphere (of 3 in. diameter). He has proposed a theoretical model for gas convection from a cavity interface, which gave the following linear relation between $p_{g 0}$ and $\alpha^{*}$ :

$$
p_{g 0} \sim 69 \alpha *(\mathrm{~Pa})
$$

where $\alpha^{*}$ is the air content (ppm). In water at $1 \mathrm{~atm}$, the maximum air content corresponding to saturation is $24 \mathrm{ppm}$ ( $9 \mathrm{ppm}$ of

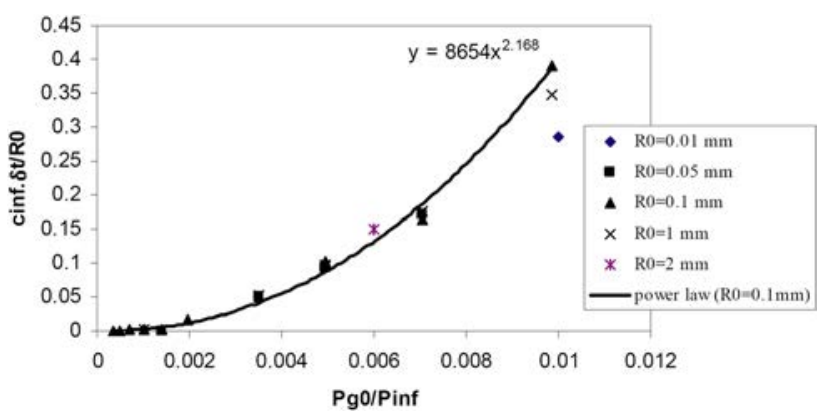

Fig. 5 Evolution of $\left(c_{\text {liq }} \delta t / R_{0}\right)$ as a function of $\left(p_{g 0} / p_{\infty}\right)$ in different cases: $2 \mathrm{~mm}<R_{0}<0.01 \mathrm{~mm}, 50 \mathrm{~Pa}<p_{g 0}<1500 \mathrm{~Pa}, 0.7$ bar $<p_{\infty}<3$ bars, $c_{\text {liq }} \sim 1500 \mathrm{~m} / \mathrm{s}$ 


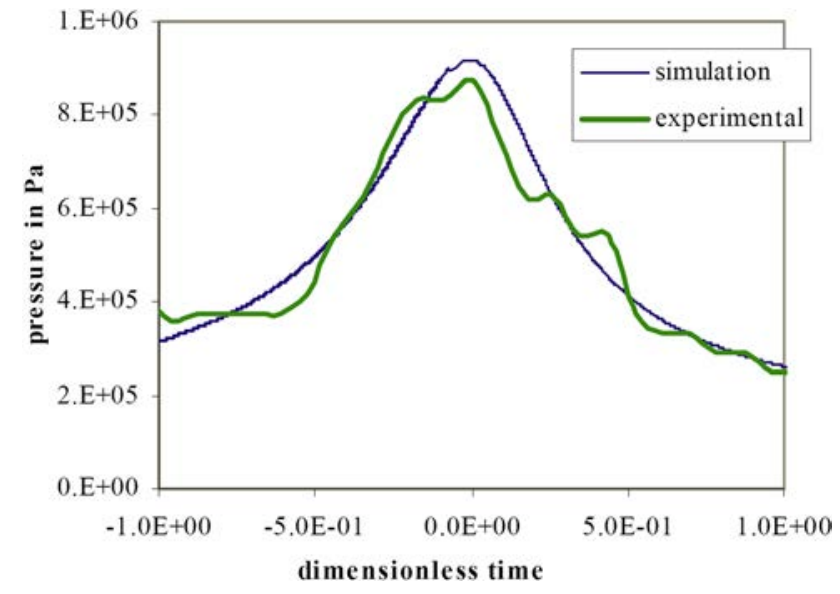

Fig. 6 Time distribution of the pressure signal at a distance of $r=8.6 \mathrm{~mm}$ from bubble center $\left(R_{0}=1 \mathrm{~mm}, p_{\infty}=1 \mathrm{~atm}\right)$. Comparison between experimental data and simulation.

oxygen and $15 \mathrm{ppm}$ of nitrogen) [39]. In the case of pressurized tests rigs, the minimum air content is about $8 \mathrm{ppm}$.

In our computations (Fig. 5), based on the results obtained in Ref. [38], we consider $p_{g 0}$ up to $1500 \mathrm{~Pa}$ and $p_{\infty}$ under 3 bars.

As illustrated by Fig. 5 , we found that there is a quite accurate relation between $c_{\text {liq }}, \delta t, R_{0}, p_{\infty}$ and $p_{\mathrm{g} 0}$

$$
\frac{c_{\mathrm{liq}} \delta t}{R_{0}}=8654\left(\frac{p_{g 0}}{p_{\infty}}\right)^{2.17}
$$

So the knowledge of $p_{\infty}, R_{0}$, and $\delta t$ (or $p_{g 0}$ ) gives out the last parameter. This relation is very useful, as we will see in the Sec. 4.4.

It is worth noting also that, for a given $p_{g 0} / p_{\infty}$ ratio, the wave passage time varies linearly with the initial bubble radius. This result agrees with experimental works performed in Ref. [34].

4.4 Comparison With Experiment. In order to validate our model, we compared our results with experiments carried out in Laboratoire Laser, Plasma et Procédés Photoniques (LP3-IRPHE) at Marseille, France [40,41]. The goals of these experiments were:

- to measure pressure wave emitted by the collapses of a single bubble generated by a laser pulse

- to observe material damage due to bubble collapses

Comparisons between numerical and experimental results were carried out.

4.4.1 Experimental Apparatus. The experimental apparatus is described in Refs. [40,41]. The bubble (with a maximum radius equal to $1 \mathrm{~mm}$ ) is created in the center of a tank by the focalization of a Nd:Yag laser beam (mono or various shots with a frequency of $1 \mathrm{~Hz}$ ). The maximal available energy is $1.3 \mathrm{~J}$ in infrared (wave length of $1064 \mathrm{~nm}$ ) and $550 \mathrm{~mJ}$ with the frequency doubler (wave length of $532 \mathrm{~nm}$ ).

Only a part of this energy (less than $5 \%$ ) is used to create the bubble; the other part is lost to an initial pressure transient and dissipated in the fluid as heat.

The pressure signal characterizing the pressure wave emitted during the bubble collapse is obtained by a PVDF transducer, placed $8.6 \mathrm{~mm}$ away from the center of the bubble (sensible area of pressure transducer of $1 \mathrm{~mm}^{2}$ and thickness of $25 \mu \mathrm{m}$ ).

4.4.2 Results. Figure 6 shows the kind of curves obtained from the experiments. One has to relate this curve to the results obtained by numerical calculations. We can observe that the shape of the signals is roughly the same, which is a first step in the validation of our model.
A second step is to simulate from the data of this signal (Fig. 6) the collapse of this bubble. Indeed, we know the surrounding pressure $p_{\infty}=1 \mathrm{~atm}$, and the initial radius $\mathrm{R}_{0}=1 \mathrm{~mm}$. The only missing parameter is $p_{g 0}$. But from the experimental curve, one can read the wave passage time $\delta t$. Making use of the Eq. (8), we are able to evaluate the initial gas pressure $p_{g 0}$ within the bubble.

In this case, $\delta t$ is about $840 \mathrm{~ns}$ and so the correlation gives $p_{g 0} \sim 1700 \mathrm{~Pa}$ (according to Ref. [38], for these values of $p_{g 0}$, the air content would be near to $24 \mathrm{ppm}$-saturated water at 1 bar). With these parameters, we ran the simulation drawn on Fig. 6. We found that the pressure wave shapes are roughly the same. Moreover, the wave amplitude obtained by simulation agrees well with measured one, and it is a part of a quantitative validation of our model.

\section{Collapse Efficiency}

To estimate the aggressiveness of cavitating flows from energy balance, we introduce a new parameter: the collapse efficiency $\eta_{\text {wave/bubble }}$ It is defined as the ratio between emitted pressure wave energy and initial potential energy $E_{\mathrm{pot}}$ of the bubble. It can be evaluated from numerical simulations by

$$
\eta_{\text {wave } / \text { bubble }}=\frac{E_{\text {wave }}}{E_{\text {pot }}}
$$

where

$$
E \text { pot }=\frac{4}{3} \pi R_{0}^{3} \Delta p
$$

where $\Delta p=p_{\infty}-p_{v}, p_{v}$ is the vapor pressure, $p_{\infty}$ is the pressure at infinity, and $R_{0}$ is the initial bubble radius. Pressure wave energy can be evaluated from total or acoustic approaches presented above.

Indeed, the collapse efficiency characterizes the aggressiveness power of the vapor/gas cavity implosion. It is related to the initial vapor volume (which is a function of $R_{0}$ ), to the initial gas pressure $p_{g 0}$ and to surrounding pressure $p_{\infty}$. Figure 7 illustrates numerical results obtained for different hydrodynamic parameters, such as $p_{g 0}, R_{0}$, and $p_{\infty}$. It appears again the strong influence of the initial gas pressure inside the bubble and of the surrounding pressure on the efficiency of the first collapse $\eta_{\text {wave/bubble. It can }}$ be seen that $\eta_{\text {wave/bubble }}$ decreases with the $p_{g 0} / p_{\infty}$ rise, and the intensity of the bubble collapse is reduced. These results agree with ones obtained in Ref. [5].

The collapse efficiency seems to depend weakly on the initial bubble radius. As a matter of fact, according to Ref. [12], smaller bubbles $\left(R_{0} \leq 0.1 \mathrm{~mm}\right)$ show increased effects of heat conduction. Hence, the assumptions taken into account in the present study are not suitable to simulate the collapse of small cavities.

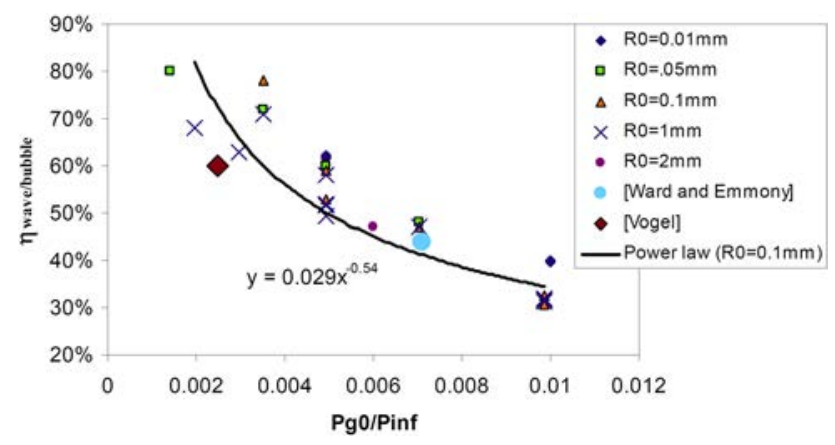

Fig. 7 Collapse efficiency as a function of $p_{g 0} / p_{\infty}$ for different initial bubble radius (efficiency calculation is based on total energy value: $E_{\text {wave }}=E_{\text {tot }}$ ). Results obtained by Refs. [14,19] are also plotted. 
Results concerning wave passage time and collapse efficiency (presented in Figs. 5 and 7) agree with experimental measurements performed by Ref. [19]. For a cavity maximum radius of about $1.1 \mathrm{~mm}$ and $\mathrm{p}_{\infty} \sim 1 \mathrm{~atm}$, they obtained a wave passage time $\delta t=140 \pm 30 \mathrm{~ns}$ and a $\eta_{\text {wave/bubble }} \sim 44 \%$. According to our simulations for the given $R_{0}$ and $\delta t\left(c_{\mathrm{liq}} \cdot \delta t / R_{0}=0.19\right)$, the pressure $p_{g 0}$ is about $710 \mathrm{~Pa}(\sim 10 \mathrm{ppm}$ according Brennen's model), and the predicted $\eta_{\text {wave/bubble }}$ is $42 \%$.

Reference [14] measured for bubble radius varying between $1<R_{0}<5 \mathrm{~mm}$, a wave passage time nearly constant ( $\left.\delta t \sim 25 \mathrm{~ns}\right)$, and a constant efficiency ( $\eta_{\text {wave/bubble }} \sim 60 \%$ for the bubble energy smaller than $30 \mathrm{~mJ}$ ). If we consider in our model the same conditions than above $\left(1<R_{0}<5 \mathrm{~mm}\right.$ and $\left.\delta t \sim 25 \mathrm{~ns}\right)$, we obtain $\left(160<p_{g 0}<340 \mathrm{~Pa}\right)$ with a mean value of $p_{g 0}$ of $250 \mathrm{~Pa}$ and a predicted collapse efficiency of about $65 \%$.

Hence, the proposed simplified model can be used to analyze bubble dynamics and to estimate hydrodynamic characteristics of the emitted pressure wave, such as, amplitude, wave passage time, energy, and mainly to predict the aggressiveness power of cavity collapses by evaluating $\eta_{\text {wave/bubble }}$.

By associating the proposed pressure wave model with an elastoplastic solid code developed in Refs. [7,42], it was possible to build a 2D axisymmetric coupled fluid-structure model to study the interaction between the pressure wave and the material surface.

\section{Interaction Between Pressure Waves and Solid Boundaries}

To study the local aspects of cavitation erosion, we performed a pressure wave-solid coupling code, which simulates the elastic response and the plastic deformation of materials subjected to the impact of spherical pressure wave emitted to a distance $L$ to the solid surface during the bubble collapses [7]. The pressure wave propagates in a spherical way into the fluid. The wave is characterized by a total energy $E_{\text {wave }}$. When the pressure wave hits the solid surface, a part of its energy is absorbed by the material, a second one is reflected, and the rest remains in the fluid in the form of spherical wave propagation. A part of the energy absorbed by the material leads to a plastic deformation if the amplitude of the pressure impact is sufficient. To simulate these energy transfers and the solid deformation, we have developed the code described here below.

6.1 Solid Code. The material's response to the pressure wave impact is calculated by a finite-element numerical code (SOLID model), which involves a Lagrangian formulation in cylindrical coordinates [42]. It takes into account the laws of continuum mechanics (mass conservation and the fundamental law of the dynamics) and an elastoplastic constitutive equation. Thermal effects are not taken into account.

The material's behavior is described by four independent factors: Young's modulus $E$, Poisson's ratio $\nu$, celerity of the longitudinal wave $C_{L}$ (involving $E, \nu$, and the material density), and a yield limit for the simple shear stress $S_{0}$. The code provides the complete transient evolution of strain, stress, and energy fields within the material and mainly the permanent surface deformation resulting from pressure wave impact. One notes that the code does not take into account the mass loss, so it can describe only the incubation stage of cavitation erosion.

The code considers symmetry conditions along the axis of revolution. The pressure spatial and temporal signal presented in the case of pressure waves emitted during bubble collapses (see Sec. 4) are used by the SOLID code as the boundary conditions at the wetted surface of the material, as illustrated by Fig. 8 .

Moreover, the other solid boundaries are considered to be nonreflecting with respect to the longitudinal and transversal stress waves.

6.2 Material Damage. According to numerical simulations concerning different materials submitted to pressure wave impacts

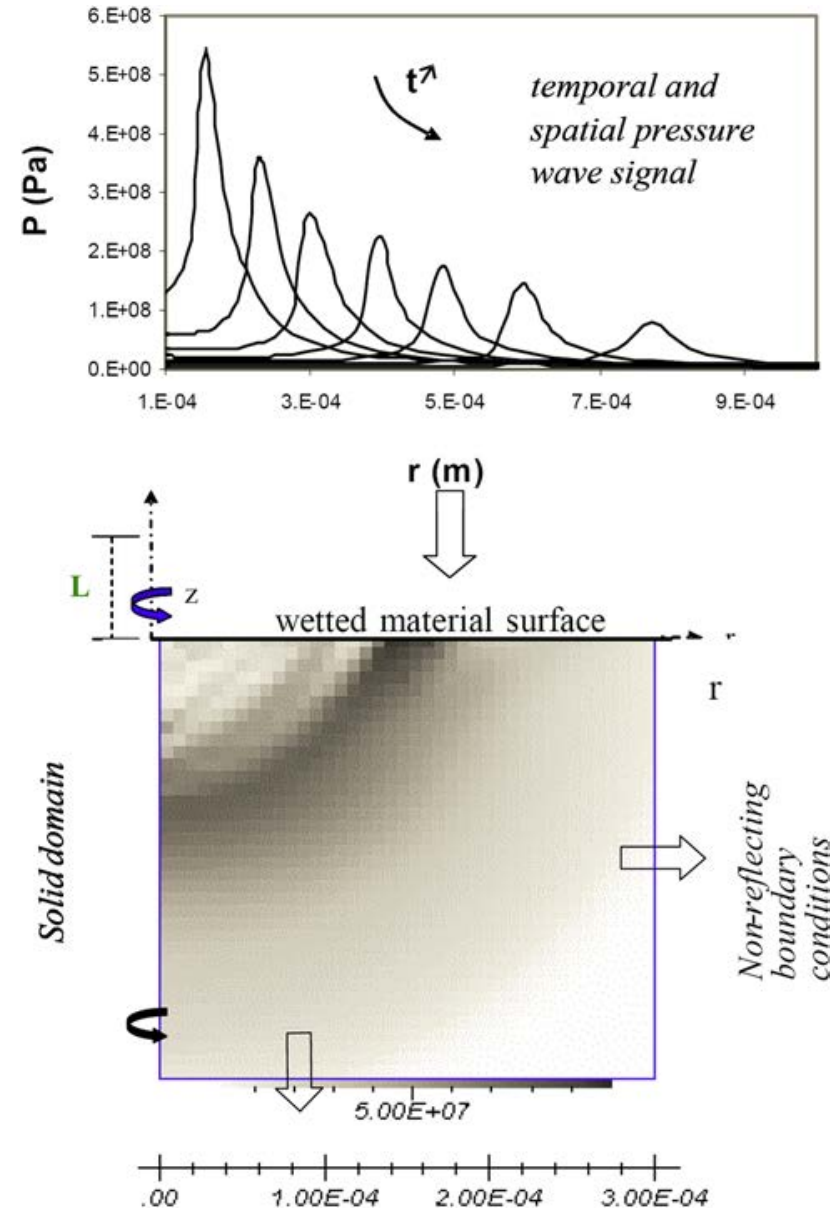

Fig. 8 (a) Spatial pressure signal applied to the solid surface at seven different times. The pressure load corresponds to the impact of a pressure wave emitted at a distance $L$ to the solid wall; $(b)$ stress field (second invariant of the deviatoric part) in the material due to the pressure wave impact at one given time. Results are given in $\mathrm{N} / \mathrm{m}^{2}$. The coordinates are cylindrical axisymmetric and only one meridian half-plane is presented.

[7], the material damage can be represented by a nondimensional axisymmetric indentation. Figure 9 illustrates the good agreement between numerical nondimensional pit profile and experimental ones observed on samples of different materials exposed to several cavitation conditions.

\section{Energy Balance}

7.1 Energy Distributions in the Material. The analysis of different energy distributions in solid and fluid domain was performed making use of the fluid-structure numerical code described above. Figure 10 presents, for instance, the distribution of energy related to internal stress $E_{i s}$ (including elastic and plastic energies)

$$
E_{i s}=\int_{0}^{t}\left(\int_{V_{s}} \operatorname{tr}(\sigma \dot{\varepsilon}) d V\right) d t
$$

and kinetic energy $E_{k}$ in the material during the impact of the pressure wave

$$
E_{k}=\int_{V s} \frac{\rho_{s}}{2}\left(v r^{2}+v z^{2}\right) d \mathrm{~V}
$$

where $\sigma$ is the stress tensor, $\dot{\varepsilon}$ is the strain rate tensor in the solid, $\rho_{s}$ is the material density, $v_{r}$ and $v_{z}$ are the radial and normal component of the velocity, and $V s$ is the volume of solid domain. 


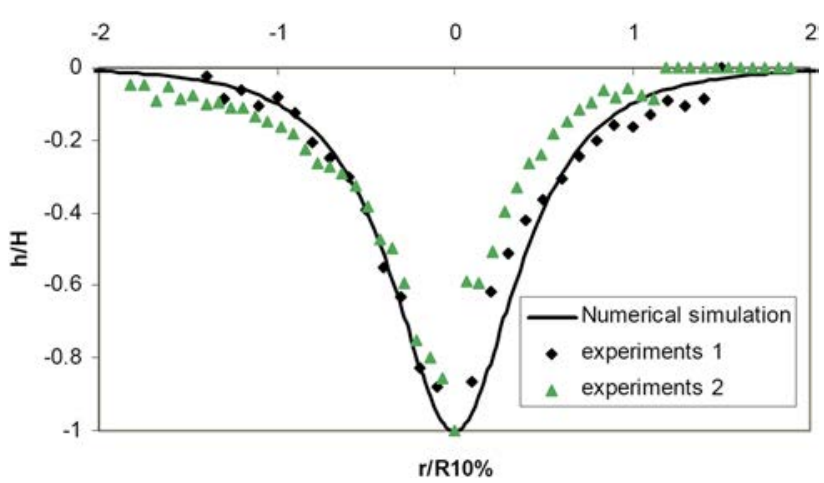

Fig. 9 Permanent surface deformation (nondimensional pit profile) calculated for pressure wave impact on material surface. Numerical results are compared with experimental ones measured by 3D laser profilometry and observed on sample surface exposed to different cavitation conditions [45]. Pit profile is characterized by the radius $R_{10 \%}$, depth $H$, and volume $V_{\text {pit }}$ obtained by trapeze integration. The damage is characterized by a plastic deformation of the surface material, without mass loss.

The internal stress energy field in the material increases quickly after the impact and represents an important part of the impact energy applied at the solid surface. It can be seen also the residual plastic energy $E_{p l}$ remaining in material after impact,

$$
E_{p l}=\lim _{t \rightarrow \infty}\left(\int_{0}^{t}\left(\int_{V_{s}} \operatorname{tr}(\sigma \dot{\varepsilon}) d V\right) d t\right)=\lim _{t \rightarrow \infty} E_{i s}
$$

One notes that the kinetic energy is weak and vanishes after the impact: Indeed, the movement generated by the dynamic loading leaves the analyzed solid volume in the form of longitudinal, transversal, and surface waves.

7.2 Energy Transfer From Pressure Wave to Solid. Concerning pressure wave calculation, the energy emitted during the wave propagation $\mathrm{E}_{\mathrm{wave}}$ is given in a good approximation by the acoustic energy approach (Eq. (5))

$$
E_{\mathrm{wave}}=\frac{4 \varsigma \pi p_{\max }^{2} r^{2}}{\rho c_{\mathrm{liq}}} \delta t=\frac{4 \varsigma \pi p_{\text {solid }}^{2} L^{2}}{4 \rho c_{\mathrm{liq}}} \delta t=\frac{\varsigma \pi p_{\text {solid }}^{2} L^{2}}{\rho c_{\mathrm{liq}}} \delta t
$$

where $p_{\text {solid }}$ is the peak pressure applied on solid surface, $L$ is the distance between wave emission center and the solid boundary, and $\delta t$ is the wave passage time. For calculations presented here

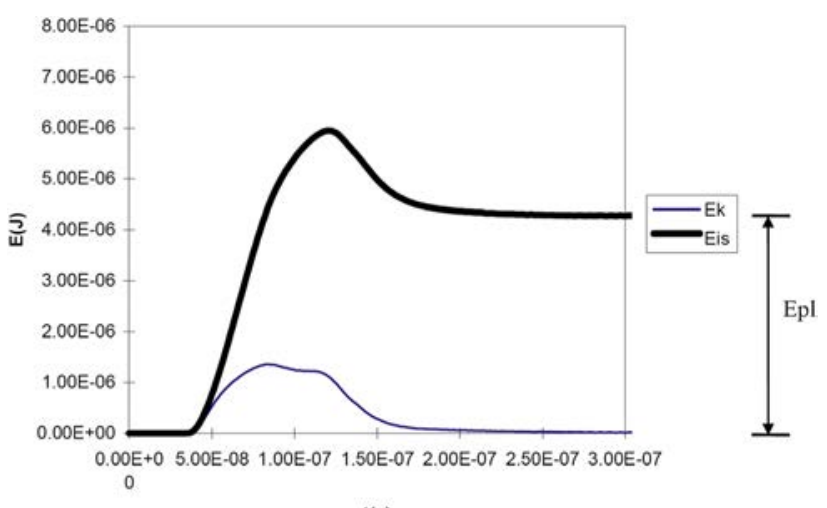

t(s)

Fig. 10 Internal stress $E_{i s}$ and kinetic $E_{k}$ energy distributions in the material during pressure wave impact on an aluminum solid sample. It can be seen the residual plastic energy $E_{p l}$ remaining in the material after impact. below, we have considered $\rho=1000 \mathrm{~kg} / \mathrm{m}^{3}, \varsigma=1, c_{\text {liq }}=1450 \mathrm{~m} / \mathrm{s}$, and $p_{\text {solid }}=2 p_{\max }$ (because when the wave impacts the solid surface one has a stagnation point, i.e., the transmission coefficient of an incident wave towards a high impedance material is considered equal to 2). The factor $\varsigma$ is related to the wave form of the pressure signal.

In this way, for a given pressure wave impact on solid surface, characterized mainly by $E_{\text {wave }}$, numerical calculations provide the energy distribution in material (mainly $E_{p l}$ and $V_{p i t}$ ). From these results, we define the erosive efficiency $\eta_{\text {solid/wave }}$ as the ratio between residual plastic energy and wave acoustic energy,

$$
\eta_{\text {solid } / \text { wave }}=\frac{E_{p l}}{E_{\text {wave }}}
$$

7.3 Material Properties. However, $E_{p l}$ is not easily measured by experimental means. As proposed by Simoneau and Archer [43], we suppose that $E_{p l}$ is linearly proportional to the pit volume, which can be measured. The proportionality factor is named $\alpha_{\text {material }}$ and depends on the material properties

$$
E_{p l}=a_{\text {material }} V_{\text {pit }}
$$

Using the erosive efficiency $\eta_{\text {solid/wave }}$, we have a relation between $V_{\text {pit }}$ and $E_{\text {wave }}$

$$
E_{\text {wave }}=\frac{E_{p l}}{\eta_{\text {solid } / \text { wave }}}=\frac{\alpha_{\text {material }} V_{\text {pit }}}{\eta_{\text {solid } / \text { wave }}}
$$

which can be simplified by introducing the parameter $\beta$

$$
E_{\text {wave }}=\beta V_{\text {pit }}
$$

where

$$
\beta=\frac{\alpha_{\text {material }}}{\eta_{\text {solid } / \text { wave }}}
$$

To improve the study of energy transfers between pressure wave energy and material damage, many numerical simulations have been done by considering different material properties and wave amplitudes. Three materials have been analyzed: aluminum, copper, and stainless steel. Table 2 gives the mechanical characteristics used by the simulations.

Detailed analyses of mesh and numerical parameters influences have been also performed. Results are presented in Ref. [44].

According to the simulations, the solid damage represented by the pit volume $V_{\text {pit }}$ seems to be directly proportional to the pressure wave energy as indicated by Fig. 11 .

We observe that the parameter $\beta$ depends strongly on the solid properties, but it is almost independent on the wave impact amplitude. It is worth noting that, for smaller impact energy, the elastic behavior of materials becomes more relevant, leading to some numerical instabilities concerning mainly solid deformation calculations.

Table 2 Material mechanical properties applied by numerical code and $\beta$ values obtained from numerical calculations. Calculations concerning stainless steel take into account the material strain hardening. $R_{m}$ is the maximum stress related to material failure.

\begin{tabular}{lcccccc}
\hline \hline & $\begin{array}{c}S_{0} \\
(\mathrm{MPa})\end{array}$ & $\begin{array}{c}E \\
(\mathrm{GPa})\end{array}$ & $\begin{array}{c}C_{L} \\
(\mathrm{~m} / \mathrm{s})\end{array}$ & $\nu$ & $\begin{array}{c}\rho \\
\left(\mathrm{kg} / \mathrm{m}^{3}\right)\end{array}$ & $\begin{array}{c}\beta \\
\left(\mathrm{J} / \mathrm{mm}^{3}\right)\end{array}$ \\
\hline Aluminum & 100 & 50 & 5000 & 0.30 & 2700 & 4 \\
Copper & 200 & 120 & 4700 & 0.33 & 8100 & 20 \\
316 L S. steel & $211\left(R_{m}=390\right)$ & 200 & 5800 & 0.30 & 7800 & 24 \\
S. steel & 400 & 200 & 5800 & 0.30 & 7800 & 90 \\
\hline \hline
\end{tabular}




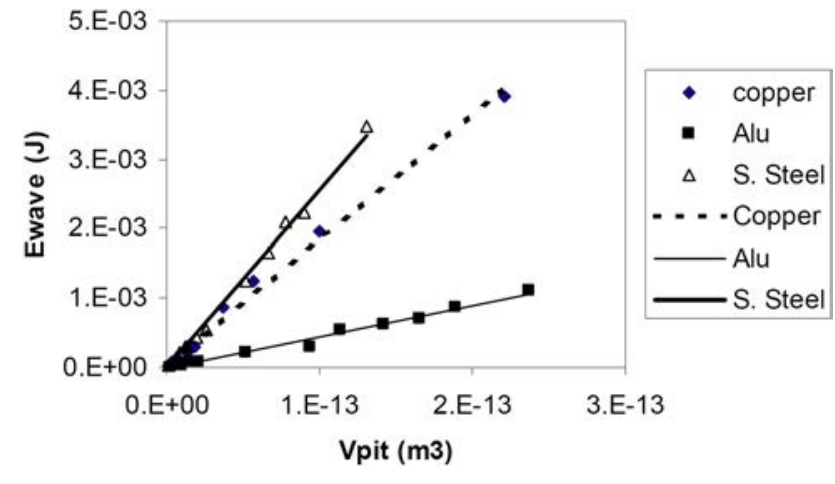

Fig. 11 The figure illustrates the relation between the pressure wave energy and pit volume obtained by numerical simulations concerning three materials (316 L SS). Based on previous work [7], the ranges of the pressure wave characteristics adopted by simulations are: $0.8 \mathrm{GPa} \leq p_{\text {solid }} \leq 4 \mathrm{GPa} ; 10 \mathrm{~ns} \leq \delta t \leq 150 \mathrm{~ns}$; $10 \mu \mathrm{m} \leq \mathrm{L} \leq 100 \mu \mathrm{m}$. The figure presents points evaluated from several calculations and the correspondent trend curves.

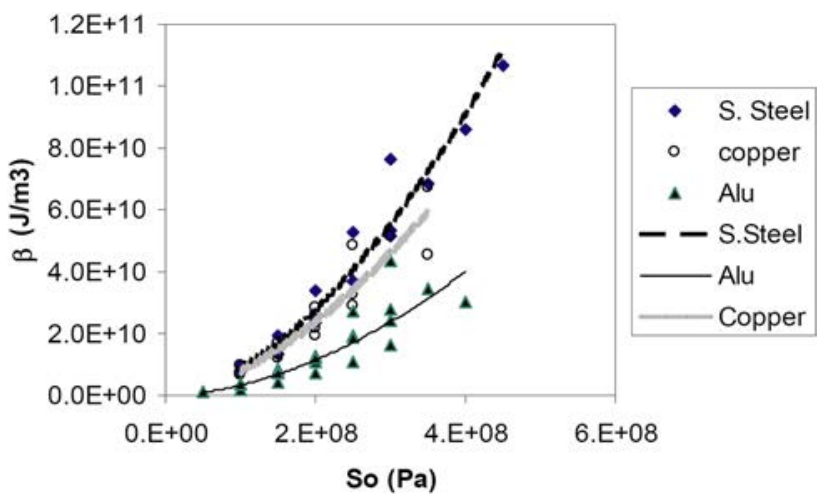

Fig. 12 Evaluation of $\beta$ parameter as a function of the stress limit $S_{0}$ : calculated points and trend curves

Figure 11 illustrates numerical results concerning the evaluation of the $\beta$ parameter for the considered materials ${ }^{3}$

$$
\begin{aligned}
\beta_{\text {aluminum }} \sim 4( \pm 0.5) \mathrm{J} / \mathrm{mm}^{3}, \beta_{\text {copper }} & \sim 20( \pm 2) \mathrm{J} / \mathrm{mm}^{3}, \\
\beta_{\text {stainless steel }} & \sim 24( \pm 2) \mathrm{J} / \mathrm{mm}^{3}\left(S_{0}=211 \mathrm{MPa}\right), \\
\beta_{\text {stainless steel }} & \sim 90( \pm 2) \mathrm{J} / \mathrm{mm}^{3}\left(S_{0}=400 \mathrm{MPa}\right)
\end{aligned}
$$

Indeed, the value of the coefficient $\beta$ is strongly related to the characteristic of the materials, mainly to the value of the yield limit for simple shear stress $S_{0}$. In order to evaluate the influence of this parameter on the evaluation of $\beta$, many simulations have been performed considering stainless steel properties $(E, \nu$, and $C_{L}$ ) for a range of $100 \mathrm{MPa} \leq S_{0} \leq 450 \mathrm{MPa}$. Results are illustrated by Fig. 12 . We can note that the $\beta$ value increases when $S_{0}$ rises, according to a power law. The same behavior was observed in the case of aluminum and copper simulations.

It is worth noting that, for calculations presented in this paper, the numerical code has used material static properties. To improve quantitative analysis, more information is needed concerning the mechanical behavior of materials at very high strain rates and their dynamic properties.

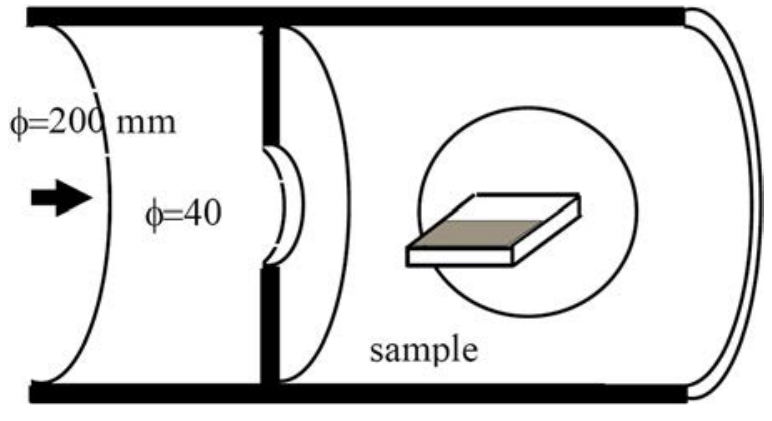

Fig. 13 MODULAB test rig. The cavitation appears in the wake zone of the jet. Generated vapor structures are convected downstream, and the samples are damaged during the collapses of these vapor structures.

\section{The Material Used as a Sensor: Some Validation Elements From Experimental Data}

Based on the results presented here above concerning the energy balance between pressure wave and material damage, the aim of this section is to evaluate cavitation intensity by analyzing pitted sample exposed to cavitating flows and gather validation data of our approach.

8.1 Experimental Study. This study involved analyzing experimental results obtained by Electricité de France [43,45] in the MODULAB test rig. Samples in several materials were damaged by water cavitating flow downstream a diaphragm, which generates jet cavitation (Fig. 13). Tests were performed for a constant cavitation number $\left(\sigma_{c}=0.7\right)$ and different water flow velocities (Table 3). Water is demineralized and deaerated. The air content is controlled with an oxygen meter and the oxygen rate is maintained less than $3 \mathrm{ppm}$.

8.2 Pitted Sample Analysis. The erosion of the sample surfaces was measured by a UBM16 laser profilometer device. According to the manufacturer, the accuracy for depth measurements is $0.06 \mu \mathrm{m}$. Pit radius measurements are made with $1 \mu \mathrm{m}$ lateral resolution.

Special software was developed to scan the surface of the pitted samples [45]. This software gives the location and size (depth « $H »$, radius $« R_{10 \%}$ ", and volume « $\left.V_{\text {pit }} »\right)$ of each individual pit. It supplies also the volume damage rate « $V d$ » (i.e., the ratio between deformed volume, analyzed sample surface, and test duration) for each analyzed sample.

$$
V d=\frac{\sum V_{\mathrm{pit}}}{\Delta S \Delta t}
$$

Generally, one assumes a linear behavior between total volume damage $\Sigma V$ and test duration $\Delta t$ (i.e., $V d$ would be constant for different test durations). Indeed, experimental study Ref. [45] seems to indicate dependence between $V d$ and $\Delta t$ for a sample surface $\Delta S$ constant. This phenomenon could be explained by the existence of superposed impacts, whose number increases with test duration $\Delta t$.

In order to perform an adequate evaluation of the volume damage rate, the measured value of $V d$ should be corrected to eliminate the influence of the test duration and of the analysis cut-off parameter (related to the measurement resolution threshold). Table 3 presents the values of the volume damage rate after correction $\left(V_{d}{ }^{\text {cor }}\right)$. The methods applied to evaluate $V_{d}^{\text {cor }}$ are detailed in Ref. [44].

8.3 Pressure Wave Power Density. To analyze samples exposed to different flow hydrodynamic conditions, the pressure 
Table 3 Experimental tests realized in MODULAB for aluminum, copper, and stainless steel samples $\left(\Delta S=100 \mathrm{~mm}^{2}\right)$

\begin{tabular}{|c|c|c|c|c|c|c|c|}
\hline$v(\mathrm{~m} / \mathrm{s})$ & $\Delta t(\mathrm{~s})$ & $V_{d}^{\text {cor }}\left(\mu \mathrm{m}^{3} / \mathrm{mm}^{2} / \mathrm{s}\right)$ & $P_{\text {wave }} / \Delta S\left(\mathrm{~W} / \mathrm{m}^{2}\right)$ & $p_{\infty}(\mathrm{Pa})$ & $p_{g 0} / p_{\infty}$ & $\eta_{\text {wave/bubble }}$ & $P_{\mathrm{pot}} / \Delta S\left(\mathrm{~W} / \mathrm{m}^{2}\right)$ \\
\hline \multirow[t]{3}{*}{20} & Aluminum: 120 & 1023 & 4.1 & \multirow[t]{3}{*}{200,000} & \multirow[t]{3}{*}{0.008} & \multirow[t]{3}{*}{$40 \%$} & 10.2 \\
\hline & Copper: 300 & 140 & 2.8 & & & & 7.0 \\
\hline & S. steel: 7200 & 69 & 6.2 & & & & 15.5 \\
\hline \multirow[t]{3}{*}{25} & Aluminum: 60 & 3087 & 12.3 & \multirow[t]{3}{*}{312,500} & \multirow{3}{*}{0.005} & \multirow[t]{3}{*}{$51 \%$} & 24.3 \\
\hline & Copper: 120 & 560 & 11.2 & & & & 22.1 \\
\hline & S. steel: 3600 & 161 & 14.5 & & & & 28.5 \\
\hline \multirow[t]{3}{*}{32} & Aluminum: 30 & 10,603 & 42.4 & \multirow[t]{3}{*}{512,000} & \multirow[t]{3}{*}{0.003} & \multirow[t]{3}{*}{$66 \%$} & 64.1 \\
\hline & Copper: 60 & 1513 & 30.3 & & & & 45.7 \\
\hline & S. steel: 1800 & 553 & 49.8 & & & & 75.2 \\
\hline \multirow[t]{3}{*}{38.5} & Aluminum: 21 & 23,912 & 95.6 & \multirow[t]{3}{*}{741,125} & \multirow[t]{3}{*}{0.002} & \multirow[t]{3}{*}{$81 \%$} & 118.5 \\
\hline & Copper: 30 & 5042 & 100.8 & & & & 124.9 \\
\hline & S. steel: 900 & 1006 & 90.5 & & & & 112.2 \\
\hline
\end{tabular}

Note: For tests conditions, see columns 1 and $2 ; V_{d}^{\text {cor }}$ measured volume damage rate; $P_{\text {wave }} / \Delta S$ calculated pressure wave power density (Eq. (22)); and $P_{\text {pot }} / \Delta S$ calculated potential power density (Eq. (23)).

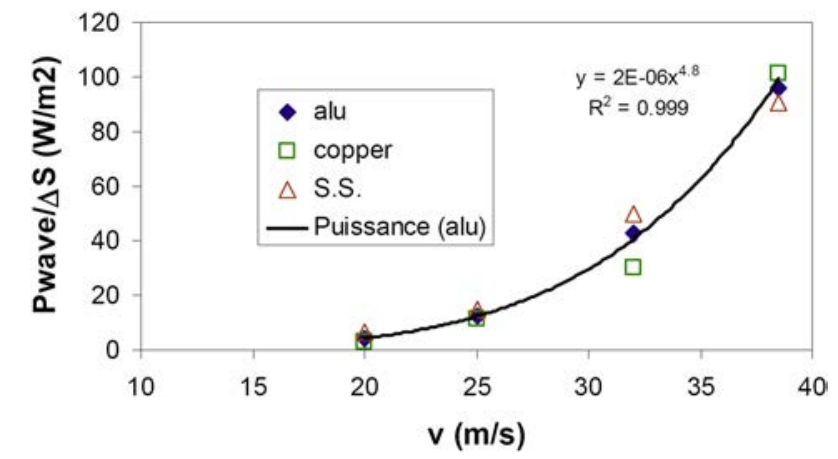

Fig. 14 Pressure wave power density (measured by three different materials) as a function of the flow velocity. For tested stainless steel samples, $S_{0} \approx 400 \mathrm{MPa}$ and $\beta \approx 90 \mathrm{~J} / \mathrm{mm}^{3}$.

wave power density $P_{\text {wave }} / \Delta S$ obtained from experimental results is introduced and is related to $V_{d}^{\text {cor }}$ through the $\beta$ parameter

$$
\frac{P_{\text {wave }}}{\Delta S}=\frac{\left(\sum E_{\text {wave }}\right)}{\Delta t \Delta S}=\beta \frac{\left(\sum V_{\mathrm{pit}}\right)}{\Delta t \Delta S}=\beta V_{d}^{\mathrm{cor}}
$$

where $\Delta S$ is the analyzed sample surface $\left(10 \times 10 \mathrm{~mm}^{2}\right)$, and $\Delta t$ is the test duration (s). ( $\left.\Sigma E_{\text {wave }}\right)$ represents the total relevant wave energy detected by the sample surface during cavitating tests.

Results concerning the evaluation of the pressure wave power density are illustrated in Fig. 14. These evaluations combine numerical prediction of $\beta$ and experimental measurements of $V_{d}^{\text {cor }}$.

It appears that for the same cavitating flow, the wave power density is constant, independently on the sample materials

$$
\frac{P_{\text {wave }}}{\Delta S}=\left(\beta V_{d}^{c o r}\right)_{\text {aluminum }}=\left(\beta V_{d}^{c o r}\right)_{\text {copper }}=\left(\beta V_{d}^{c o r}\right)_{\text {stainless steel }}
$$

This result was physically expected, since the overall cavitating flow is not influenced by local pits. This result is, therefore, considered as an element to validate our energy approach.

Pressure wave power density increases approximately as $P_{\text {wavel }}$ $\Delta S \sim v^{5}$ as illustrated by Fig. 14 .

8.4 Potential Power Density of Vapor Structures. Based on the physical scenario proposed in Sec. 1, we can also relate the flow aggressiveness potential power to the collapse efficiency by

$$
\left.P_{\mathrm{pot}}=\frac{1}{\eta_{\text {wave } / \text { bubble }}}\right) P_{\text {wave }}
$$

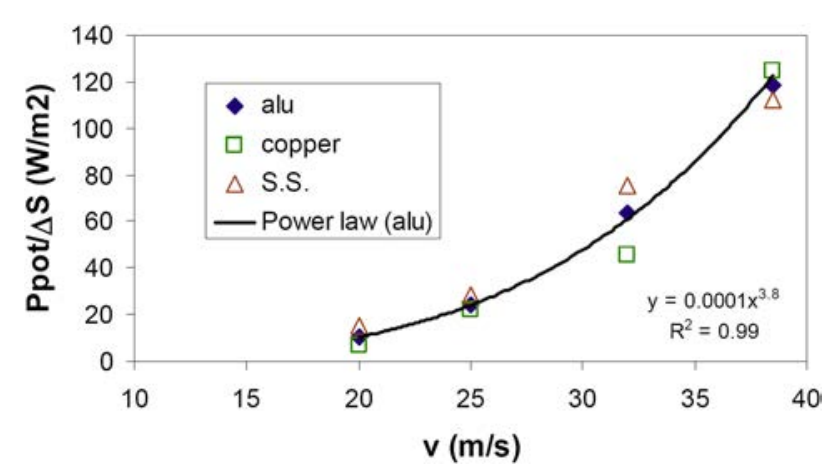

Fig. 15 Flow aggressiveness potential power density (evaluated for three different materials) as a function of the flow velocity. For tested stainless steel samples, $S_{0} \approx 400 \mathrm{MPa}$ and $\beta \approx 90 \mathrm{~J} / \mathrm{mm}^{3}$.

and the associated surface density

$$
\left.\frac{P_{\text {pot }}}{\Delta S}=\frac{1}{\eta_{\text {wave } / \text { bubble }}}\right) \frac{P_{\text {wave }}}{\Delta S}
$$

where the efficiency $\eta_{\text {wave/bubble }}$ is modeled by the collapse of spherical bubbles of vapor and noncondensable gas. It depends mainly on the pressure $p_{\infty}$ and on the air content in the flow. Table 3 and Fig. 15 give results obtained by considering $p_{g 0} \sim 1500 \mathrm{~Pa}, p_{\infty}=\rho v^{2} / 2$, and $\eta_{\text {wave/bubble }}$ values obtained from Fig. 7. Flow aggressiveness potential power increases approximately as $P_{\text {pot }} / \Delta S \sim v^{3.8}$ as illustrated by Fig. 15. It appears also that for the same cavitating flow, $P_{\text {pot }} / \Delta S$ is constant, independently on the sample materials. This result is a second element to validate the energy approach proposed.

Thus, flow aggressiveness potential power and pressure wave power density seem to well represent the cavitation aggressiveness of the flow and can be related to the flow hydrodynamic characteristics $\left(v, p_{\infty}\right.$, air content, geometric scale). It is important to note that according to the proposed approach:

- The cavitation intensity depends on the air content in the flow.

- The influence of flow velocity on $P_{\text {pot }} / \Delta S$ and on $P_{\text {wave }} / \Delta S$ is not the same because $\eta_{\text {wave/bubble }}$ depends on the flow velocity.

\section{Conclusion}

A physical scenario concerning cavitation damage phenomenon was proposed. The approach relates the vapor volume of the 
cavity to the material damage by means of the pressure wave characteristic.

A theoretical and numerical modeling of vapor/gas bubble collapse was developed. Pressure waves generated during cavity implosion were studied, and characteristic parameters (such as wave passage time, wave amplitude, and emitted energy) were calculated as a function of hydrodynamic conditions (i.e., surrounding pressure, air content, and bubble radius). We found a dimensionless shape for the pressure wave, whatever the hydrodynamic are. The study also pointed out the strong influence of the air content on the bubble dynamic and mainly on the pressure wave characteristics. The aggressiveness power of cavity implosion was evaluated by means of the collapse efficiency, defined as the ratio between pressure wave energy and initial bubble energy.

The interaction between the pressure wave emitted during the vapor structures' collapses and the neighboring solid boundaries was analyzed by means of numerical calculations concerning spherical bubble implosions and material deformation.

The permanent surface deformation calculated for pressure wave impact on material surface seemed to be well characterized by a nondimensional pit profile.

According to the simulations, material damage (represented by pit volume) is directly related to the pressure wave energy via the mechanical coefficient $\beta$, characteristic of solid behavior.

The analysis of pitted samples exposed to cavitating flows associated with numerical calculations led to the evaluation of the flow aggressiveness potential power and the pressure wave power density, characteristic of flow cavitation intensity. Results indicated that the evaluation of these power densities and the mechanical coefficient $\beta$ is a useful tool in the prediction of cavitation erosion concerning:

- the influence of solid properties on material damage

- the effect of flow velocity on cavitating flow aggressiveness

\section{Acknowledgment}

This study was supported by EDF-Electricité de France (R\&D Division) and by a doctoral grant from the Education French Ministry MERT.

\section{Nomenclature}

\section{Liquid/Bubble, Pressure Wave Emission} (Dots Denote Differentiation With Respect to Time)

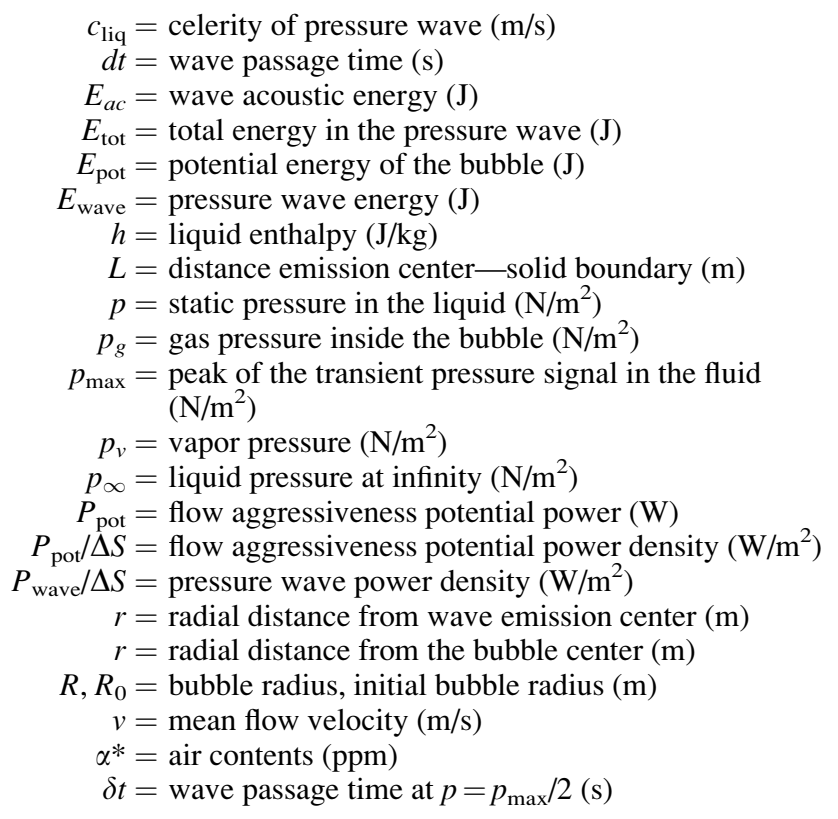

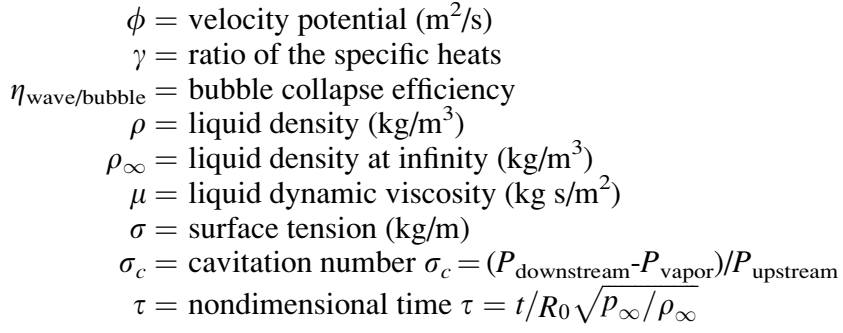

Solid

$C_{L}=$ celerity of longitudinal waves $(\mathrm{m} / \mathrm{s})$

$E=$ Young's modulus $\left(\mathrm{N} / \mathrm{m}^{2}\right)$

$E_{i s}=$ internal stress energy $(\mathrm{J})$

$E_{k}=$ kinetic energy $(\mathrm{J})$

$E_{p l}=$ residual plastic energy in the material $(\mathrm{J})$

$H=$ pit depth (m)

$p_{\text {solid }}=$ peak pressure applied on solid surface $\left(\mathrm{N} / \mathrm{m}^{2}\right)$

$R_{10 \%}=$ pit radius at $10 \%$ of $\mathrm{H}(\mathrm{m})$

$S_{0}=$ yield limit for simple shear stress $\left(\mathrm{N} / \mathrm{m}^{2}\right)$

$V_{\mathrm{pit}}=$ volume of the pit generated by pressure wave $\left(\mathrm{m}^{3}\right)$

$\alpha_{\text {material }}=\eta_{\text {solid } / \text { wave }} \beta\left(\mathrm{J} / \mathrm{mm}^{3}\right)$

$\eta_{\text {solid/wave }}=$ erosive efficiency

$\beta=$ mechanical characteristic coefficient $\left(\mathrm{J} / \mathrm{mm}^{3}\right)$

$\nu=$ Poisson's ratio

\section{Pitted Samples (the Term "Pit" is Used to Refer} to the Plastic Deformation Observed on the Material Surface)

$$
\begin{aligned}
P_{\text {total }} / \Delta S & =\text { potential power density }\left(\mathrm{W} / \mathrm{m}^{2}\right) \\
P_{\text {wave }} / \Delta S & =\text { pressure wave power density }\left(\mathrm{W} / \mathrm{m}^{2}\right) \\
V_{d} & =\text { volume damage rate }\left(\mu \mathrm{m}^{3} / \mathrm{mm}^{2} / \mathrm{s}\right. \\
V_{d}^{\text {cor }} & =\text { corrected volume damage rate }\left(\mu \mathrm{m}^{3} / \mathrm{mm}^{2} / \mathrm{s}\right) \\
\Delta S & =\text { analyzed sample surface }\left(\mathrm{m}^{2}\right) \\
\Delta t & =\text { test duration (s) }
\end{aligned}
$$

\section{References}

[1] Kato, H., Konno, A., Maeda, M., and Yamaguchi, H., 1996, "Possibility of Quantitative Prediction of Cavitation Erosion Without Model Test," ASME J. Fluids Eng., 118(3), pp. 582-588.

[2] Pereira, F., Avellan, F., and Dupont, P., 1998, "Prediction of Cavitation Erosion: An Energy Approach,” ASME J. Fluids Eng., 120(4), pp. 719-727.

[3] Hattori, S., Hirose, T., and Sugiyama, K., 2010, "Prediction Method for Cavitation Erosion Based on Measurement of Bubble Collapse Impact Loads," Wear, 269, pp. 507-514.

[4] Franc, J. P., 2009, "Incubation Time and Cavitation Erosion Rate of WorkHardening Materials," ASME J. Fluids Eng, 131(2), p. 021303.

[5] Dular, M., Stofel, B., and Sirok, B., 2006, "Development of a Cavitation Erosion Model," Wear, 261, pp. 642-655.

[6] Steller, J., and Krella, A., 2007, "On Fractional Approach to Assessment of Material Resistance to Cavitation," Wear, 263, pp. 402-411.

[7] Fortes-Patella, R., and Reboud, J. L., 1998, "A New Approach to Evaluate the Cavitation Erosion Power," ASME J. Fluids Eng., 120(2), pp. 335-344.

[8] Fortes-Patella, R., Challier, G., and Reboud, J. L., 1999, "Study of Pressure Wave Emitted During Spherical Bubble Collapse," Proceedings of ASME, Paper No. FEDSM99-6756.

[9] Fortes-Patella, R., Challier, G., Reboud, J. L., and Archer, A., 2001, "Cavitation Erosion Mechanism: Numerical Simulations of the Interaction Between Pressure Waves and Solid Boundaries," Proceedings of CAV 2001 Symposium, June 2001, Pasadena, CA.

[10] Lord Rayleigh, 1917, "On the Pressure Developed in a Liquid During the Collapse of a Spherical Cavity," Philos. Mag., 34(200), pp. 94-98.

[11] Prosperetti, A., 1994, "Bubbles Dynamics: Some Things we did not Know 10 Years Ago," Bubble Dynamics and Interface Phenomena, J. Blake, J. BoultonStone, and N. Thomas, eds., Kluwer Academic Publishers, Dordrecht, The Netherlands, pp. 3-15.

[12] Fujikawa, S., and Akamatsu, T., 1980, "Effects of Non-Equilibrium Condensation of Vapor on the Pressure Wave Produced by Collapse of a Bubble in Liquid,” J. Fluid Mech., 97(3), pp. 481-512.

[13] Plesset, M., and Chapmann, R., 1971, "Collapse of an Initially Spherical Vapor Cavity in the Neighborhood of a Solid Boundary," J. Fluid Mech., 47(2), pp. 283-290.

[14] Vogel, A., Lauterborn, W., and Timm, R., 1989, "Optical and Acoustic Investigations of the Dynamics of Laser-Produced Cavitation Bubbles Near a Solid Boundary,” J. Fluid Mech., 206, pp. 299-338.

[15] Matsumoto, Y., 1998, "Bubble Dynamics in Cavitation," Proceedings of the 3rd International Symposium on Cavitation, Grenoble, France. 
[16] Brujan, E. A., Keen, G. S., Vogel, A., and Blake, J. R., 2002, "The Final Stage of the Collapse of a Cavitation Bubble Close to a Rigid Boundary," Phys. Fluids, 14(1), pp. 85-92.

[17] Lindau, O., and Lauterborn, W., 2003, "Cinematographic Observation of the Collapse and Rebound of a Laser-Produced Cavitation Bubble Near a Wall,"J. Fluid Mech., 479, pp. 327-348.

[18] Kroninger, D., Kohler, K., Kurz, T., and Lauterborn, W., 2010, "Particle Tracking Velocimetry of the Flow Field Around a Collapsing Cavitation Bubble," Exp. Fluids, 48, pp. 395-408.

[19] Ward, B., and Emmony, D. C., 1990, "The Energies and Pressures of Acoustics Transients Associated With Optical Cavitation in Water," J. Mod. Opt., 37(4), pp. 803-811.

[20] van der Meulen, J. H. J., and van Renesse, R. L., 1993, "The Collapse of LaserInduced Bubbles Near a Solid Boundary and the Generation of Pressure Pulses," Cavitation and Multiphase Flow Forum (FED Series), Vol. 153, O. Furuya, ed., ASME, Washington, DC, pp. 127-132.

[21] Bourne, N. K., 2002, "On the Collapse of Cavities," Shock Waves, 11, pp. $447-455$.

[22] Philipp, A., Ohl, C. D., and Lauterborn, W., 1995, "Single Bubble Erosion on a Solid Surface," Proceedings of the International Symposium on Cavitation (CAV1995), Deauville, France, pp. 297-303.

[23] Chen, X., Xu, R. Q., Shen, Z. H., Lu, J., and Ni, X. W., 2004, "Optical Investigation of Cavitation Erosion by Laser-Induced Bubble Collapse," Opt. Lase Technol., 36, pp. 197-203.

[24] Tomita, Y., and Shima, A., 1986, "Mechanisms of Impulsive Pressure Generation and Damage Pit Formation by Bubble Collapse," J. Fluid Mech., 169, pp. 535-564.

[25] Kawanami, Y., Kato, H., Yamaguchi, H., Tanimura, M., and Tagaya, Y., 1987, "Mechanism and Control of Cloud Cavitation," ASME J. Fluids Eng., 119(4), pp. 788-794.

[26] Buravova, S. N., and Gordopolov, Y. A., 2010, "Bubble Induced Cavitation Effect Upon Solid Surfaces," Tech. Phys. Lett., 36(8), pp. 717-719.

[27] Prosperetti, A., and Lezzi, A., 1986, "Bubble Dynamics in a Compressible Liquid. Part I: First Order Theory,” J. Fluid Mech., 168, pp. 457-478.

[28] Herring, C., 1941, "Theory of the Pulsations of the Gas Bubble Produced by an Underwater Explosion," OSRD Report No. 236

[29] Beeching, R., 1942, "Resistance to Cavitation Erosion," Trans. Inst. Eng. Shipbuild. Scotl., 85, pp. 210-276.

[30] Poritski, M., 1952, "The Collapse or the Growth of a Spherical Bubble or Cavity in a Viscous Fluid," Proceedings of the 1st U.S. National Congress of Applied Mechanics (ASME), pp. 813-821.
[31] Keller, J. B., and Kolodner, I. I., 1956, "Damping of Underwater Explosion Bubble Oscillation,” J. Appl. Phys., 27(10), pp. 1152-1161.

[32] Gilmore, F. R., 1952, "The Collapse and Growth of a Spherical Bubble in a Viscous Compressible Liquid," California Institute of Technology Hydrodynamics Laboratory, Report No. 26-4.

[33] Cole, R. H., 1948, Underwater Explosions, Dover Publications, New York.

[34] Lindau, O., 2001, "Untersuchungen zur laserzeugten Kavitation," Ph.D. thesis, Georg-August-Universität, Göttingen, Germany.

[35] Fortes-Patella, R., and Reboud, J. L., 1998, "Energetical Approach and Impact Efficiency in Cavitation Erosion," Proceedings of 3rd International Symposium on Cavitation, Grenoble, France.

[36] Lovik, A., and Vassenden, J., 1977, "Basic and Applied Aspects of Scaling Cavitation Noise," Proceedings of the Conference on Scaling for Performance Prediction in Rotordynamic Machines, University of Stirling, Stirling, UK.

[37] Knapp, R. T., Daily, J. T., and Hammit, F. G., 1970, Cavitation, McGraw-Hill, New York.

[38] Brennen, C., 1969, "The Dynamic Balances of Dissolved Air and Heat in Natural Cavity Flows," J. Fluid Mech., 37(1), pp. 115-127.

[39] Franc, J.-P., Avellan, F., Belahadji, B., Billard, J. Y., Briançon-Marjollet, L., Frechou, D., Fruman, D. H., Karimi, A., Kueny, J.-L., and Michel, J. M., 1995, La Cavitation: Mécanismes Physiques et Aspects Industriels, Collection Grenoble Science, University of Grenoble, Grenoble, France.

[40] Isselin, J. C., Alloncle, P., and Autric, M., 1998, "Investigations of Material Damages Induced by an Isolated Vapor Bubble Created by Pulsed Laser," Proceedings of the 3rd International Symposium on Cavitation, Grenoble, France.

[41] Isselin, J. C., Alloncle, P., and Autric, M., 1998, "On Laser Induced Single Bubble Near a Solid Boundary: Contribution to the Understanding of Erosion Phenomena," J. Appl. Phys., 84(10), pp. 5766-5771.

[42] Reboud, J. L., and Guelin, P., 1988, "Impact Response of an Elastoplastic Medium," Mech. Res. Commun., (15)4, pp. 253-260.

[43] Simoneau, R., and Archer, A., 1997, "Transposition of Cavitation Marks on Different Hardness Metals," Proceedings of the ASME Fluids Engineering Division Summer Meeting, Vancouver, Canada.

[44] Challier, G., 2002, "Mécanismes d'Interaction Fluide/Structure et de Transfert d'Energie en Erosion de Cavitation," Ph.D. thesis, Institut Polytechnique de Grenoble, Grenoble, France.

[45] Fortes-Patella, R., Reboud, J. L., and Archer, A., 2000, "Cavitation Mark Measurements by 3D Laser Profilometry," Wear, 246, pp. 59-67. 